\title{
Communication/Comunicação
}

\section{Outbreak of neonatal infection by an endemic clone of Serratia marcescens}

\author{
Surto de infecção neonatal a partir de clone endêmico de Serratia marcescens
}

\section{Karla Valéria Batista Lima ${ }^{1}$, Raimundo Gladson Corrêa Carvalho ${ }^{2}$, Irna Carla do Rosário Souza Carneiro ${ }^{3}$,Josiane Lílian de Sousa Lima ${ }^{3}$, Cintya de Oliveira Sousa ${ }^{1}$, Edvaldo Carlos Brito Loureiro ${ }^{1}$, Lena Líllian Canto de Sá and Flávia Corrêa Bastos ${ }^{1}$}

\begin{abstract}
Introduction: The outbreak occurred between February and June 2006 and included identification of the cases, analysis of medical records, cultures from environmental sources, resistance analyses and genotyping profile of Serratia marcescens. Methods: The cultures were composed of 13 blood isolates, 17 rectal and hand swabs and air sampling. Results: The data obtained by pulsed-field gel electrophoresis exhibited three strains that contaminated 24 patients. Systemic infection was the most common in neonates with lower weight, long periods of hospitalization, premature delivery and the use of mechanical ventilation. Conclusions: This investigation revealed the multifactorial nature of the outbreak. An endemic clone of S. marcescens was detected.
\end{abstract}

Keywords: Serratia marcescens. Outbreak. Nosocomial infection.

\section{RESUMO}

Introdução: O surto ocorreu entre fevereiro a junho de 2006 e incluiu identificação de casos, análise dos prontuários, culturas ambientais, análise de resistência e genotipagem dos isolados de Serratia marcescens. Métodos: Os cultivos foram compostos de 13 isolados de sangue e 17 swabs de reto e mãos e amostras do ar. Resultados: Os dados obtidos por eletroforese de campo pulsado evidenciaram três cepas que contaminaram 24 pacientes. Infecção sistêmica foi mais comum em neonatos com menor peso, longo tempo de internação, nascimento prematuro e uso de respiração mecânica. Conclusões: Foi evidenciada a natureza multifatorial do surto. Foi encontrado um clone endêmico de $S$. marcescens.

Palavras-chaves: Serratia marcescens. Surto. Infecção hospitalar.

Intensive care units are often involved in epidemics of Serratia marcescens colonization and infection. Important reservoirs in epidemics are the digestive, respiratory and urinary tracts and perineum of neonates and the artificial nails of adults and healthcare workers (HCWs) ${ }^{1}$. Medical equipment, lotions, antiseptics, medications and sinks have also been described as sources of such epidemics ${ }^{2,3}$. Transient transportation of $S$. marcescens on the hands of medical personnel is considered an important mode of transmission in epidemics ${ }^{2}$.

The associations for neonatal infection by $S$. marcescens include low birth weight, long-term hospitalization, mechanical ventilation, invasive procedures and exposure to antibiotics and steroids ${ }^{2}$.

1. Bacteriology and Mycology Section, Evandro Chagas Institute, Ananindeua, PA, Brazil. 2. Cytology Department, State University of Para, Belém, PA, Brazil. 3. Health Department, State University of Para, Belém, PA. 4. Environment Section, Evandro Chagas Institute, Ananindeua, PA, Brazil.

Address to: Dra. Karla Valéria Batista Lima. Instituto Evandro Chagas/ SABMI. Rodovia BR $316 \mathrm{Km}$ 7, s/n, 67030-000 Ananindeua, PA.

Phone: $55913214-2116$

e-mail: karlalima@iec.pa.gov.br

Received in 26/02/2010

Accepted in 06/10/2010
The occurrence of infections by $S$. marcescens in the neonatal intensive care unit (NICU) of reference in Belém motivated the development of this work, in order to establish the genotypic profile of this pathogen and contribute to the control of healthcareassociated infection (HCAI).

\section{Characterization of the institution and of the samples}

The study was developed in a neonatal unit (NU) of high complexity, located in the City of Belém, State of Pará. The unit is composed of an internal nursery (IN), for children born in the hospital, a neonatal intensive care unit (NICU) and an external nursery (EN). The IN is divided into five wards: special care (SC), intermediate care (IC), semi-intensive (SI), other disorders and the transition room.

\section{Microbiological methods}

From February to June 2006, 1,445 hemocultures were performed, as well as several other cultures: 375 rectal swabs from newborns, 127 from the hands of HCWs, 21 of water from the humidifier, 11 from drugs, alcohol and detergents, 10 involving air sampling in the environment, 5 from the humidifier filter, 5 of the water tap and 5 from the doorknob of the neonatal unit door. The hemocultures were performed in an automated system BACTEC 9,120 (Becton Dickinson) and the others were seeded on sheep blood agar (Difco), Cled agar (Difco) and Mac-Conckey agar (Difco) and incubated in a bacteriological incubator (Fanem) at $37^{\circ} \mathrm{C}$ for $24 \mathrm{~h}$.

Air was collected using AMS100 equipment (Merck), calibrated to collect $250 \mathrm{~L}$ of air in $2 \mathrm{~min} 50 \mathrm{sec}$, which contained a 15/90mmPetri dish with Cled agar (Difco).

The colonies originating from Gram negative bacilli, negative oxidase, were suspended in saline solution and incubated in a GNI+ card for bacterial identification and in a GNS 655 card (BioMerieux) for susceptibility assays, in accordance with the manufacturer's recommendations.

For evaluation of the sensibility to ertapenem, the methodology proposed by Clinical and Laboratory Standards Institute (CLSI) was used ${ }^{4}$.

\section{Pulsed-field gel electrophoresis}

Chromosomal DNA was extracted from stored $S$. marcescens isolates. DNA was digested with $\mathrm{XbaI}$ and PFGE was performed in electrophoresis system CHEF-DR III, Bio-Rad ${ }^{5}$.

Pulsed-field gel electrophoresis profiles were analyzed using BioNumerics software (Applied Maths, Sint-Martens-Latem, Belgium) and the similarity of fragment length patterns between two strains was scored by the Dice coefficient ( $4 \%$ of tolerance). 


\section{Case: control study}

To determine associations with $S$. marcescens infection or colonization, a case-control study was conducted comparing casepatients (Table 1) with other neonates, who had been admitted to the NICU between February and June 2006. The medical records were reviewed to identify sex, birth weight, gestational age, delivery, length of hospitalization and reason for hospitalization. Based on these studies, each case was matched to a selected control. A case was defined as being a neonate with infection or colonization by S. marcescens. The controls were neonates who were hospitalized in the NICU during the same period but did not get infected or colonized.

\section{Statistical analysis}

Odds ratios, 95\% confidence intervals and two-sided $p$ values were calculated using the BioEstat software, version 5.0. The level of statistical significance adopted was $\mathrm{p}<0.05$.

\section{Ethical considerations}

The development of this work was approved by the Research Ethics Committee of the Evandro Chagas Institute under protocol CEP/ IEC no. 003/07, of 14 June 2007.

\section{Results and discussion}

The total number of positive cultures was composed of 13 isolates from hemocultures, 13 from rectal swabs, 2 from hand swabs, 2 from air sampling, 2 from blood collected some months after the outbreak and 3 from other NUs (PFGE profile 01, 15, 16). Cultures of water from the humidifier, from drugs, alcohol and detergents, the humidifier filter, water tap and doorknob of the neonatal unit door did not detect $S$. marcescens.

The grouping of the isolates identified by macro restriction fragment patterns resolved by PFGE exhibited 11 to 16 fragments ranging from 48.5 to $533.5 \mathrm{~kb}$. Typing of the outbreak-related isolates demonstrated that three epidemic strains with distinct fingerprints were associated with cross-infection (Figure 1). Eight patterns contained one isolate and the remaining 27 isolates were grouped into three clusters, containing 3 to 14 isolates. The first isolate of S. marcescens in group 1 (samples 4-13) was obtained on February $10^{\text {th }}$ from EN14. Additional occurrences were observed in other wards (NICU and IC), 8 of them isolated from the NICU and two isolated in the EN and IC (Figure 1).

Group 2 was the largest; the first event was observed on March $7^{\text {th }}$ from SC14, followed by dispersions to other wards. Samples 18 and 19 were isolated in the NU from blood of neonates attended some months after the outbreak. The samples of group 3 were dispersed over the months of February, March and June. The antibiotic susceptibility profiles were different for all three clinical isolates. They showed $82.78 \%$ similarity with group 2 .

The case-control study showed that neonates with $S$. marcescens were more likely to have a lower birth weight, long-term hospitalization, premature delivery and exposure to continuous positive airway pressure (Table 1).

All the isolates of the $S$. marcescens outbreak were resistant to ampicillin and the association of ampicillin and sulbactam and $74.3 \%$ of the evaluated samples presented resistance to the $\beta$-lactams piperacillin associated with the inhibitor of $\beta$-lactamases tazobactam. The index of resistance to the aminoglycosides gentamicin and amikacin was also high in this work (Table 1). Both were susceptible to ertapenem.
TABLE 1 - Distribution of 26 patients according to clinical, demographic variables and the occurrence of neonatal infection.

\begin{tabular}{|c|c|c|c|c|c|}
\hline & \multicolumn{2}{|c|}{ Cases } & \multicolumn{2}{|c|}{ Controls } & \multirow{2}{*}{$\begin{array}{r}\text { Odds ratio } \\
\mathrm{p}\end{array}$} \\
\hline & $\mathrm{n}$ & $\%$ & $\mathrm{n}$ & $\%$ & \\
\hline \multicolumn{6}{|l|}{ Gender } \\
\hline male & 14 & 53.9 & 15 & 57.7 & 0.8556 \\
\hline female & 12 & 46.2 & 11 & 42.3 & 1.0000 \\
\hline \multicolumn{6}{|c|}{ Birth weight } \\
\hline$<2,500$ & 24 & 92.3 & 13 & 50.0 & 12.0000 \\
\hline$\geq 2,500$ & 2 & 7.7 & 13 & 50.0 & 0.0020 \\
\hline
\end{tabular}

\begin{tabular}{|c|c|c|c|c|c|}
\hline \multicolumn{6}{|l|}{ Delivery } \\
\hline cesarean & 9 & 34.6 & 9 & 34.6 & \\
\hline vaginal & 17 & 65.4 & 17 & 65.4 & \\
\hline \multicolumn{6}{|c|}{ Length of hospitalization (days) } \\
\hline$>11$ & 3 & 11.5 & 17 & 65.4 & 0.0756 \\
\hline$\geq 11$ & 21 & 80.8 & 9 & 34.6 & 0.0004 \\
\hline \multicolumn{6}{|c|}{ Maternal age (years) } \\
\hline$<19$ & 4 & 15.4 & 7 & 26.9 & 0.8352 \\
\hline$>19$ & 13 & 50.0 & 19 & 73.1 & 0.9139 \\
\hline \multicolumn{6}{|c|}{ Premature delivery } \\
\hline yes & 19 & 73.1 & 11 & 42.3 & 5.1818 \\
\hline no & 5 & 19.2 & 15 & 57.7 & 0.0178 \\
\hline \multicolumn{6}{|c|}{ Respiratory distress syndrome } \\
\hline yes & 8 & 30.8 & 2 & 7.7 & 5.3333 \\
\hline no & 18 & 69.2 & 24 & 92.3 & 0.0785 \\
\hline \multicolumn{6}{|c|}{ Surgical procedures } \\
\hline yes & 3 & 11.5 & 7 & 24.1 & 0.3540 \\
\hline no & 23 & 89.7 & 19 & 75.9 & 0.2912 \\
\hline \multicolumn{6}{|c|}{ Orogastric tube } \\
\hline yes & 20 & 76.9 & 15 & 57.7 & 2.9333 \\
\hline no & 5 & 19.2 & 11 & 42.3 & 0.1572 \\
\hline \multicolumn{6}{|c|}{ Continuous positive airway pressure } \\
\hline yes & 24 & 92.3 & 15 & 57.7 & 8.8000 \\
\hline no & 2 & 7.7 & 11 & 42.3 & 0.0104 \\
\hline
\end{tabular}

Internal nursery is recognized as one of the most significant causes of morbidity and mortality among hospitalized newborns, especially in NICUs ${ }^{6}$. However, the exact impact of this condition is difficult to determine, since a wide variation in infection rates is reported in the literature, possibly due to differences in surveillance or study methods. It is important to control the inherent aspects of each NICU and to make the data available to the local health authorities, healthcare workers and the scientific communityinterested in epidemiological data. Unfortunately, this practice is still not universal and there are few published studies that portray the epidemiology and risk factors for NI in Brazilian NICUs.

The overall NI incidence rates reported in Brazilian NICUs of $30.6 \%^{7}$ and $22 \%{ }^{8}$ are much higher than those observed in most studies in the United States $(11.4 \%)^{9}$ or Europe $(2.5 \%)^{10}$.

The results obtained suggest cross-transmission between patients during the period of study. The colonized or infected neonates were the principal reservoir of $S$. marcescens in these outbreaks, as previously reported ${ }^{1}$. The initial source and the mode of introduction to the NICUs remain unclear. For group 1, it is possible that the index case was the neonate admitted on February $10^{\text {th }}$ and that later, other neonates in others wards were infected. Sample 10, which was isolated from the hands of a HCW, may have spread the microorganisms to other neonates in the NU. 


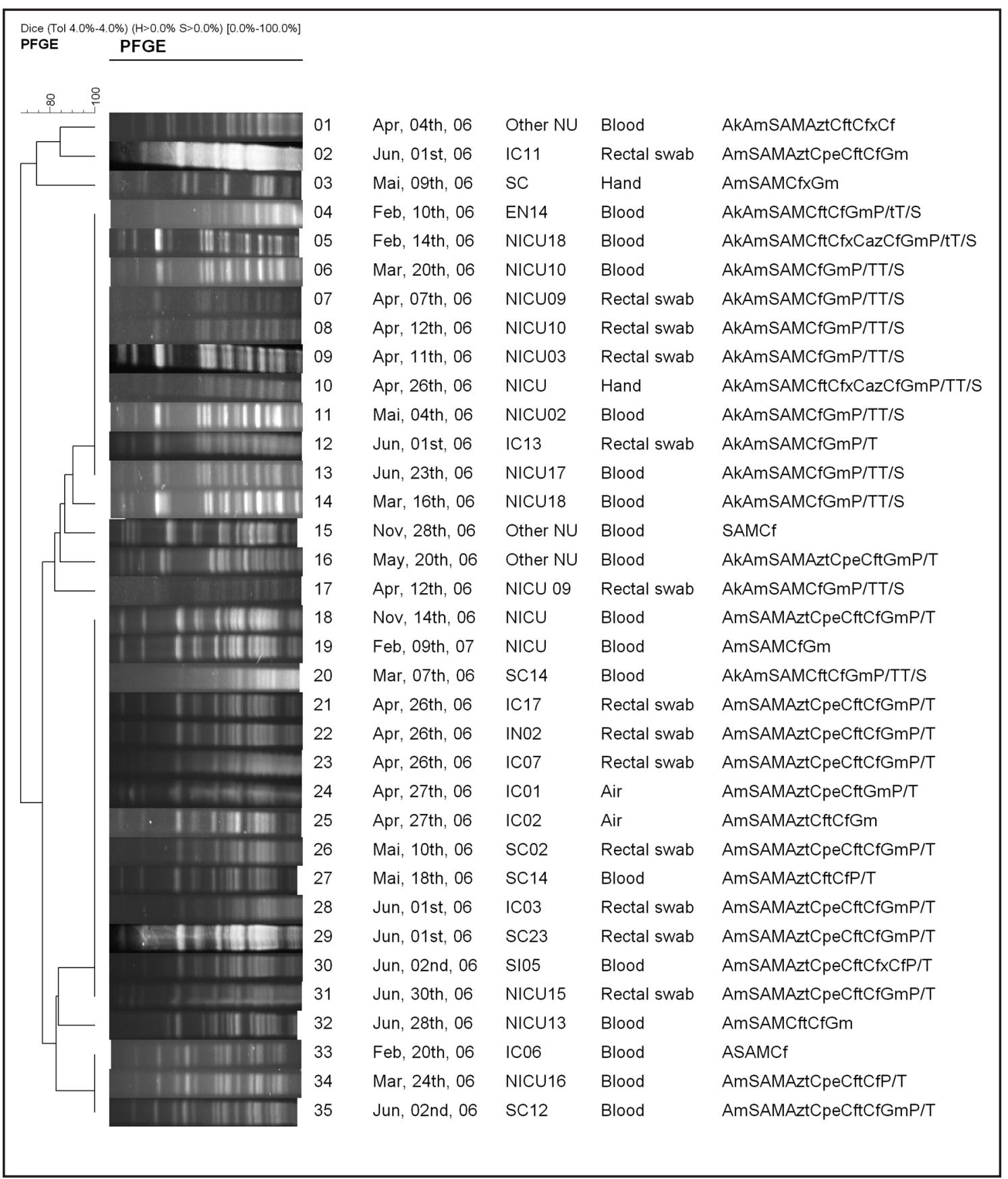

FIGURE 1 - Correlation of pulsed-field gel electrophoresis profile, isolation date, localization in the neonatal unit, site of isolation and resistance profile.

Ak: amikacin, Am: ampicillin, SAM: ampicillin-Subactan, Azt: aztreonan, Cpe: cefepime, Cft: cefotaxime, Cfx: cefoxitin, Caz: ceftazidime, Cf: cephalothin, Gm: gentamicin, P/Z: piperacillin-tazobactam, T/S: trimethoprim-sulfametoxazole, EN: external nursery, IC: intermediate care, IN: internal nursery, NICU: neonatal intensive care unit, NU: neonatal unit, SC: special care, SI: semi-intensive.

The S. marcescens-positive HCW was known by colleagues to strictly adhere to hand hygiene procedures. Observational studies concerning hand hygiene during the epidemic were not performed; however, inspection of the hands of the HCW excluded the presence of rings, artificial nails and psoriasis. Rings, artificial fingernails and psoriasis can harbor gram-negative rods ${ }^{11}$. Group 2 presented the more prevalent clone that affected ten neonates in 2006. The genotyping data also revealed that the $S$. marcescens strain (genotype 18 and 19) was identified in the same NICU some months after the outbreak, suggesting an endemic situation. The same clone was isolated from the air of the NICU. Subsequent isolates with similar patterns suggest that prolonged, persistent person-to-person transmission of strains occurred. During the outbreak, patients were transferred from the NICU to surgery units and readmitted to the NICU in cases of patient deterioration. Another problem is related to the HCWs assisting in different wards in the NU. The actions outlined above facilitated the dissemination of the outbreak strains between different wards.

Low birth weight, longer periods of hospitalization, premature delivery and exposure to continuous positive airway pressure were risk factors for NICU acquired infections. In this study the majority of patients had low birth weight. Brito et al also reported that a large proportion $(92.3 \%)$ of cases presented low birth weight and prematurity ${ }^{12}$. 
Waterless, alcohol-based hand antiseptic has been shown to be more effective than antimicrobial soap in eliminating pathogens from the hands. McNeil et al demonstrated that only $11 \%$ of HCWs with artificial nails who had pathogens at baseline effectively removed the pathogens using soap compared to $38 \%$ using alcohol-based ge ${ }^{13}$. Of those HCWs who had natural nails and pathogens at baseline, $14 \%$ removed the pathogens using soap compared to $80 \%$ of those using an alcohol-based antiseptic $(p=0.09)$. The introduction of alcoholbased hand antiseptic to the NICU effectively provided easy access to another method of hand hygiene, which may have contributed to more frequent hand washing between contacts with patient.

After the outbreak, several infection control measures were introduced at the same time, including the alcohol-based hand antiseptic; therefore, it is difficult to identify which measures were responsible for controlling the infection. Some months after the outbreak, two new NI (18 and 19 samples, Figure 1) were observed, but they were controlled. Future outbreak control measures should concentrate on the intensity of colonization, not only of the neonates, but also of the mothers and HWCs ${ }^{1,14,15}$. The antibiotic use and prophylaxis in mothers should be evaluated on a case-by-case basis, thus limiting the potential for broad-spectrum antibiotics to select multiresistant Gram-negative bacteria.

The association tazobactam with piperacilin has been used as an alternative for treatment of HCAI caused by Gram-negative bacilli and anaerobes producers of $\beta$-lactamases. In the NICU studied, tazobactam with piperacilin should not have been used for S. marcescens infection.

Although genotyping has no influence on the therapy, clinicians should forward isolates for epidemiological research because genotyping can help trace infection sources and is useful in infection control and epidemiological surveys of hospital infections, particularly on the neonatal ward. The lack of cases in 2008 , following the implementation of infection control measures to prevent spread, serves as additional evidence that this epidemic of $26 \mathrm{~S}$. marcescens cases was indeed due to transmission.

Genotyping was available and showed identical strains in the NICU in the clusters, confirming that cross-infection occurred. However, S. marcescens most likely acted only as an indicator. It is possible that other pathogens were being horizontally transmitted at the same time, but they were not investigated and thus were not detected.

This investigation showed the multifactorial nature of the development of clusters caused by $S$. marcescens. These outbreaks seldom have only one cause or source, but are more likely due to several factors. Attention should be paid to healthcare workers, the mothers and the neonates, in addition to general risk factors and infection control policies, to ensure an adequate healthcare workerto-patient ratio.

\section{ACKNOWLEDGMENTS}

The authors would like to thank Dr Iracina de Jesus of the Environment Section of the Evandro Chagas Institute for her collaboration and Henri Berghs for the English language review.

\section{CONFLICT OF INTEREST}

The authors declare that there are no conflicts of interest.

\section{FINANCIAL SUPPORT}

Universidade do Estado do Pará (UEPA), Instituto Evandro Chagas (IEC), Conselho Nacional de Desenvolvimento Científico e Tecnológico $(\mathrm{CNPq})$ and Fundação de Amparo à Pesquisa do Estado do Pará (FAPESPA).

\section{REFERENCES}

1. Vries JJ, Baas WH, Van der Ploeg K, Heesink A, Degener JE, Arends JP. Outbreak of Serratia marcescens colonization and infection traced to a healthcare worker with long-term carriage on the hands. Infect Control Hosp Epidemiol 2006; 27:1153-1158.

2. Lai KK, Baker SP, Fontecchio SA. Rapid eradication of a cluster of Serratia marcescens in a neonatal intensive care unit: use of epidemiologic chromosome profiling by pulsed-field gel electrophoresis. Infect Control Hosp Epidemiol 2004; 25:730-734.

3. Buffet-Bataillon S, Rabier V, Bétrémieux P, Beuchée A, Bauer M, Pladys P, et al. Outbreak of Serratia marcescens in a neonatal intensive care unit: contaminated unmedicated liquid soap and risk factors. J Hosp Infect 2009; 72:17-22.

4. Clinical and Laboratory Standards Institute. Performance standards for antimicrobial susceptibility testing. Fifteenth informational supplement. Wayne: CLSI NCCLS Publication 2005; M100-S15.

5. Gauton RK. Rapid pulsed-field gel electrophoresis protocol for typing of Escherichia coli O157:H7 and other Gram-negative organisms in 1 day. J Clin Microbiol 1997; 35:2977-2980.

6. Pessoa-Silva CL, Dharan S, Hugonnet S, Touveneau S, Posfay-Barbe K, Pfister R, et al. Dynamics of bacterial hand contamination during routine neonatal care. Infect Control Hosp Epidemiol 2004; 25:192-197.

7. Pinheiro MSB, Nicoletti C, Boszczowsk I, Puccini DMT; Ramos STTS Nosocomial infections at Neonatal Intensive Care Unit: does the place of birth matter? Rev Paul Pediatr 2009; 27:6-14.

8. Pessoa-Silva CL, Richtmann R, Calil R, Santos RM, Costa ML, Frota AC, et al. Healthcareassociated infections among neonates in Brazil. Infect Control Hosp Epidemiol 2004; 25:772-777.

9. Sohn AH, Garrett DO, Sinkowitz-Cochran RL, Grohskopf LA, Levine GL, Stover BH, et al. Prevalence of nosocomial infections in neonatal intensive care unit patients: results from the first national point-prevalence survey. J Pediatr 2001; 139:821-827.

10. Raymond MDJ, Aujard MDY. Nosocomial Infections in Pediatric Patients A European, Multicenter Prospective Study. Infect Control Hosp Epidemiol $2000 ; 21: 260-264$

11. Larson EL, Cimiotti JP, Haas J, Nesin M, Allen A, Della-Latta P, et al. Gramnegative bacilli associated with catheter-associated and non-catheter-associated bloodstream infections and hand carriage by healthcare workers in neonatal intensive care units. Pediatr Crit Care Med 2005; 6:457-461.

12. Brito DVD, Matos C, Abdalla V, Augusto Filho D, Filho G, Pinto P. An outbreak of nosocomial infection caused by ESBLs producing Serratia marcescens in a Brazilian neonatal unit. Braz J Infect Dis 1999; 3:149-155.

13. McNeil SA, Foster CL, Hedderwick SA, Kauffman CA. Effect of hand cleansing with antimicrobial soap or alcohol-based gel on microbial colonization of artificial fingernails worn by health care workers. Clin Infect Dis 2001; 32:367-372.

14. Sarvikivi E, Lyytikäinen O, Salmenlinna S, Vuopio Varkila J, Luukkainen P, Tarkka E, et al. Clustering of serratia marcescens infections in a neonatal intensive care unit. Infect Control Hosp Epidemiol 2004; 25:723-729.

15. Palos MAP, Silva DVB, Gir E, Canini SR, Anders PS, Leão LSN, et al Microbiota das mãos de mães e de profissionais de saúde de uma maternidade de Goiânia. Rev Eletr Enf 2009; 11:573-578. 